the rare occasions, when this happens, important organs like the mandibles, antennæ, labium, maxillæ, palpi and eyes.are kept scrupulously free from the parasitic growth. Although, as previously stated, many of the L. neoniger bristled with the Laboulbenia, there were scattered over their chitinous integument numerous minute black dots representing the points of attachment of fungi that had been completely torn away, either by attrition against the walls of the nest galleries, or more probably, by the strigils and tongues of the ants themselves. The observations at Ellisville indicate that the parasitic fungus can luxuriate only on the members of ant-colonies which have become enfeebled or depauperate through nesting in soil which is too moist, saline or foul, or of an abnormally high temperature when exposed to the sun.

\title{
ON THE REPUGNATORIAL SECRETION OF CARABUS VINCTUS.
}

A rather unexpected occurrence happened at the capture of my first specimen of this species, which I had discovered under some old boards near the Shawshine River in Andover, Mass. I picked it up between the thumb and finger for a closer examination and, when perhaps a foot from my face, heard a slight snapping noise which was followed by the sensation that might be produced by the application of red hot needles to one's face. This intense burning lasted until I bathed my face in alcohol. Since then I have taken two specimens in Framingham and, in each case, noticed the same snapping noise, but as I took good care not to get the insect very near my face, I did not experience the previous unpleasant results.

The elytral edges are strongly reflexed in this beetle and at the apices a slight hollow is formed which would hold a small quantity of the fluid secreted; and when the elytra receive the pressure of the thumb and finger they snap past each other and the resultant spring throws the fluid off in a fine spray.

\author{
C. A. Frost.
}




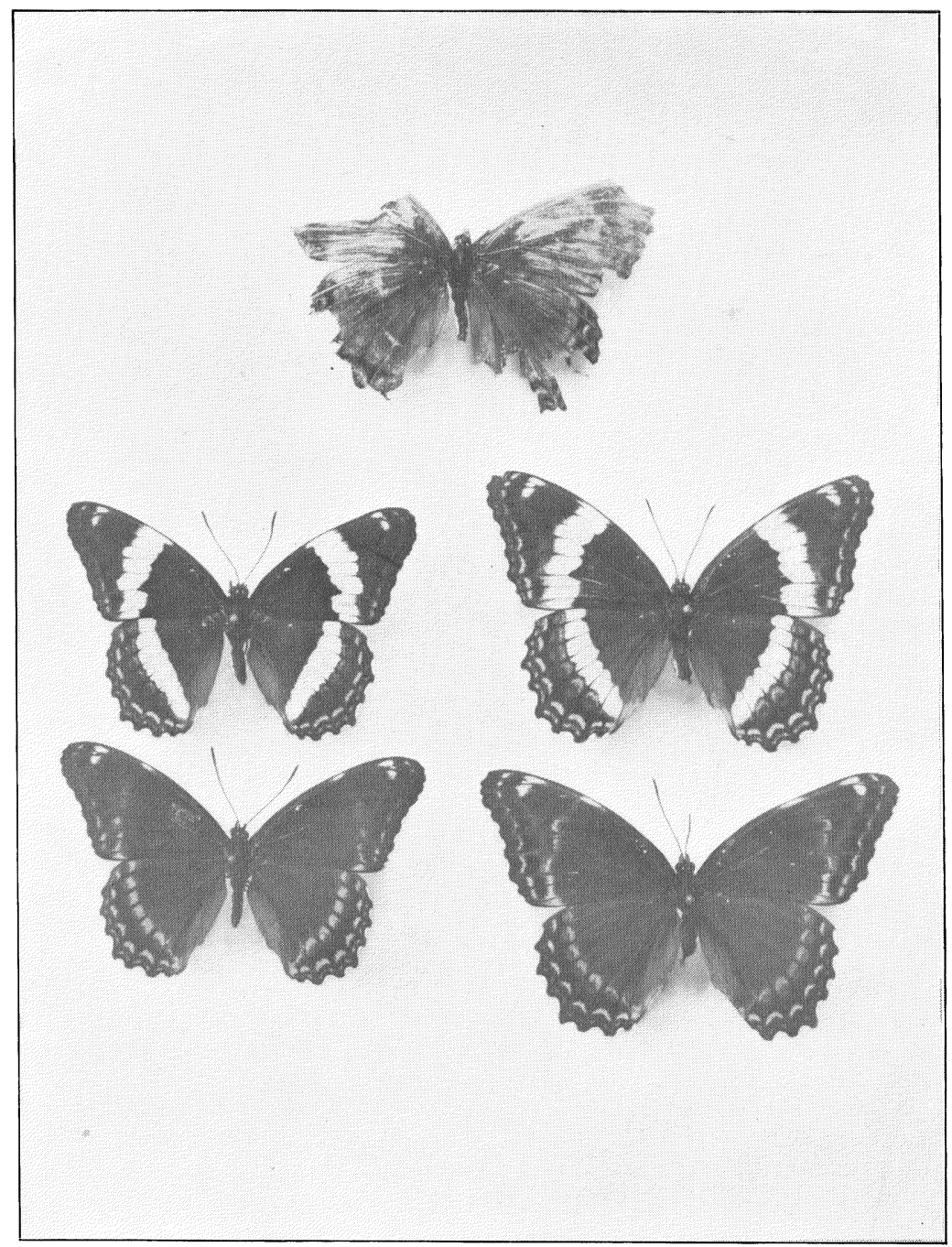

FIELD-BUTTERFLIES OF THE GENUS BASILARCHIA. 

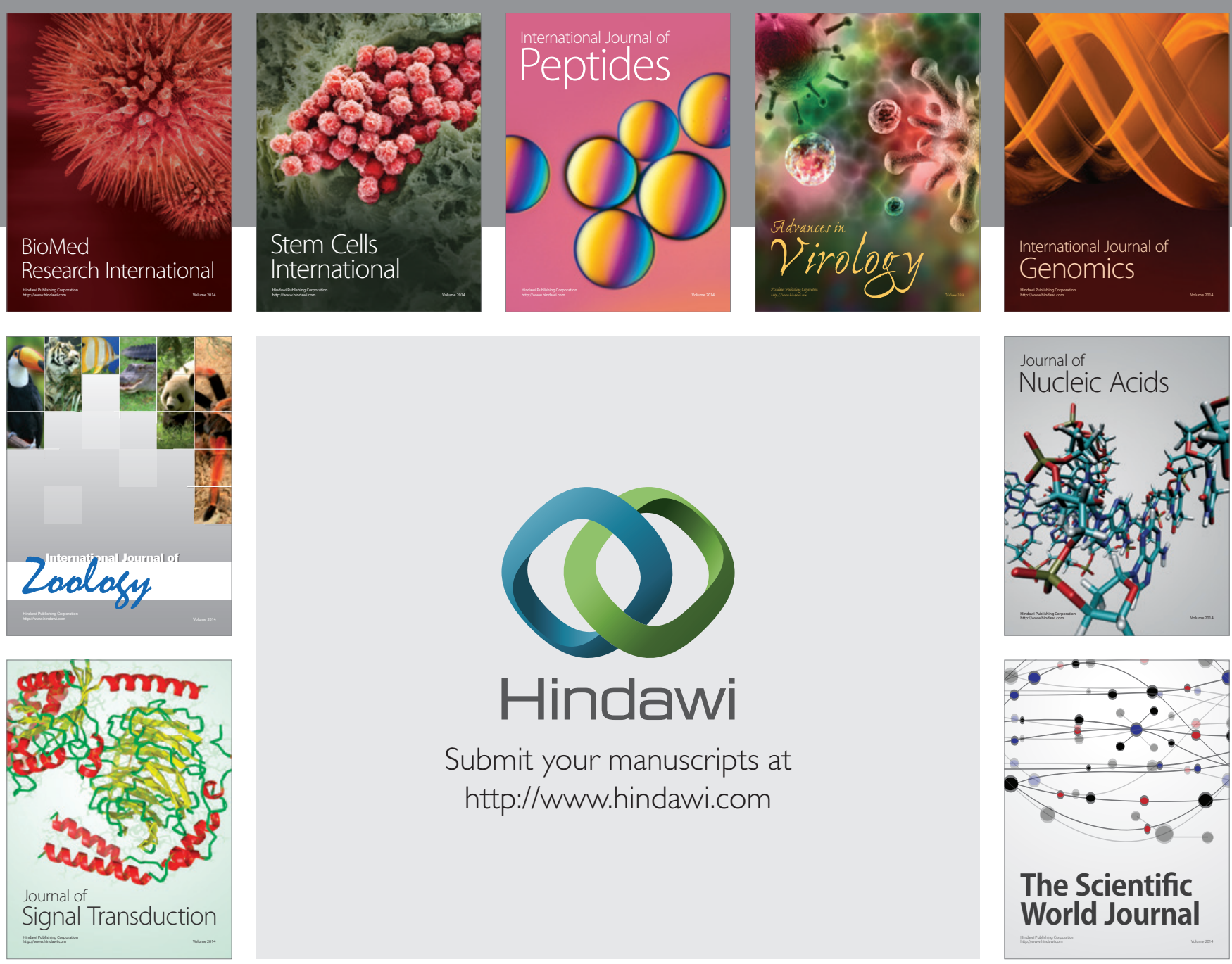

Submit your manuscripts at

http://www.hindawi.com
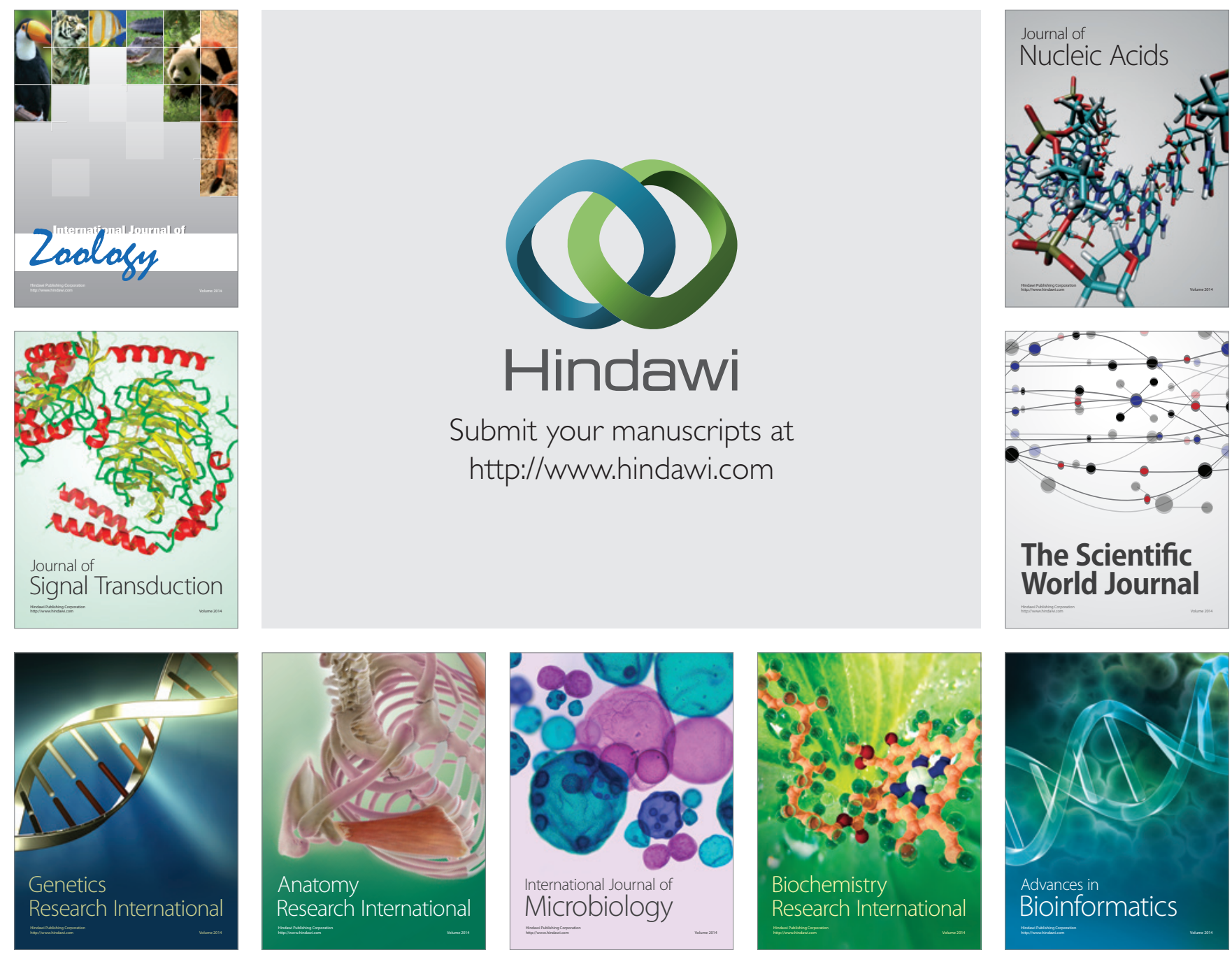

The Scientific World Journal
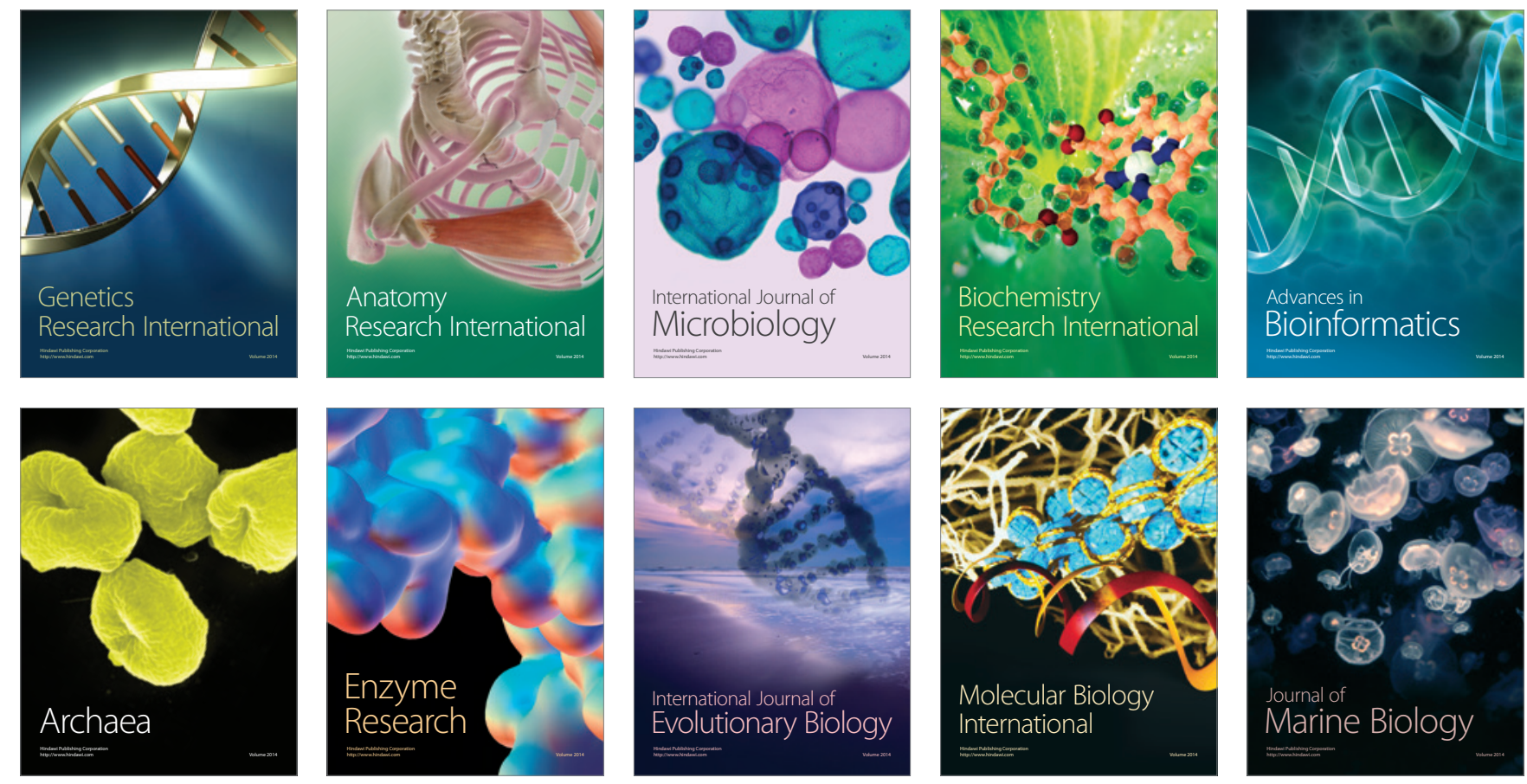